\title{
An Efficient Functionality Learning Image Compression by Ift Technique
}

\author{
C.Rajeswari, S.Prakasam
}

\begin{abstract}
Image compression is the course towards apportioning an image into different size as adaptable for the customer to proceed, recollecting a definitive goal to change the depiction of a photo into something that is more fundamental and less referencing to survey. Value learning has been done in the zone of image compression. Since, most of the compression cycle just depends upon quality images. In Image compression, the quality of image is more important than other fields.This paper follows the regular Image picture division as a depiction issue and joins handiness getting the hang of recollecting as extreme goal to help the client from picking where to give sharp information. Explicitly part, our proposed structure overviews a surrendered division by building a "dubiousness field" over the image area thinking about cut-off, normal, flawlessness and entry terms. The client can continue managing the rule of the information on the solicitation plane, in this manner current giving extra preparing information where the classifier has the base conviction. Our strategy portrayals against capricious plane confirmation demonstrating a normal DSC [Dice similarity coefficient] change of $19 \%$ in the hidden five plane proposals (pack questions).
\end{abstract}

Key Words: Image compression, Functionality Learning, DSC [Dice similarity coefficient], Ambiguity Field, image view.

\section{INTRODUCTION}

Image compression is one of, if not the most, significant and omnipresent undertakings in clinical image examination. Completely manual cut by cut compression of images is generally perceived as infeasible, being excessively dreary, tedious, costly, and[1][4] experiencing high between and intra-administrator fluctuation. Moreover, manual administrators have exceptionally restricted capacity to incorporate the data accessible in Image information given that practically all showcases and information section instruments. On another side of the range, completely robotized compression procedures have by and large attempted to accomplish the precision and power levels required for clinical practice. Therefore, exceptionally computerized intuitive image compression approaches [1][4] have as of late become the methodology of decision in most genuine clinical applications, and in this manner are collecting the focal point of the clinical image investigation network. Usefulness learning (FL) [2][4] alludes to directed AI where, rather than the client; a part of the calculation called the 'question methodology' is answerable for picking the preparation information to be named.

Revised Manuscript Received on October 25, 2020.

* Correspondence Author

C.Rajeswari*, Research Scholar, SCSVMV University, Kanchipuram, India. E-mail: rajic13@gmail.com

Dr.S.Prakasam, Asst. Professor, Department of Computer Science \& Applications, SCSVMV University, Kanchipuram, India. E-mail: sp@kanchiuni.ac.in

(c) The Authors. Published by Blue Eyes Intelligence Engineering and Sciences Publication (BEIESP). This is an open access article under the CC BY-NC-ND license (http://creativecommons.org/licenses/by-nc-nd/4.0/)
The inquiry system, having private information on the internal activities of the particular grouping calculation conveyed, is in an incredible situation to decide competitor excellent preparing information voxels. By marking voxels as indicated by FL inquiries, intelligent compression calculations can create improved compressions utilizing less, more productive client input. Intuitive compression is frequently an iterative cycle. A client gives input that guides calculations which return yield back to the client so they may give extra information. In a perfect world, the collaboration cycle can happen continuously with the goal that clients get prompt criticism on their activities. [1][4] For the situation where client cooperation appears as determining which voxels have a place with the item or area of premium (ROI) and which don't, the intuitive compression cycle can be pleasantly defined inside an administered AI system. The client information would thus be able to be viewed as marked preparing information, which the intelligent compression calculation, or classifier, uses to name the rest of the information (for example to compressingthe ROI). Image compression alludes to the way toward limiting an advanced image into different fragments for example set of pixels, pixels in a district are comparable as indicated by some homogeneity standards, for example, shading, force or surface, in order to find and recognize items and limits in an image [3][30] Practical use of image compression range from separating of boisterous images, clinical applications Face Recognition, Finger print Recognition, and so forth. Numerous compression techniques have been proposed in the writing. The decision of a compression method over another and the [30] level of compression are chosen by the specific sort of image and qualities of the issue being thought of.

\section{LITERATURE SURVEY}

Anca Stefanoiu.et.al; proposed the Segmentingmultidimensional informational indexes, for example, information from processed tomography (CT), video information, or evenimage acquisitions concerning occasion emerging from attractive reverberation imaging (MRI) information of a thumping heart, one normally gets a solitary, however an entire assortment of shapes. These shapes ordinarily appreciate a characteristic spatial, worldly, or even spatiotemporal requesting. In video groupings for instance, the shapes relating to a followed object have a characteristic transient requesting. Another model is organ compression, where the compression is performed done cut savvy. The subsequent shape assortment, gotten from diagrams of the compressions, appreciates a characteristic spatial requesting actuated by the requesting of the cuts.

Published By:

Blue Eyes Intelligence Engineering

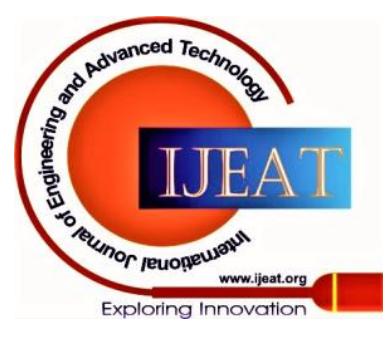




\section{An Efficient Functionality Learning Image Compression by Ift Technique}

Kaustav Nandy et.al;shows a programmed, vigorous and exact Image atomic pressure calculation focused at cell cores in thick tissues of higher life forms. pressure was started by a novel seed discovering strategy dependent on vigorous and precise $2 \mathrm{D}$ cut by cut pressure of the Image volume and ID of planned inward seed focuses for every individual core. Hence, every individual core was compressedby a chart cut-based calculation which was motivated by past works in open pit mining [6] [7] and clinical image pressure [8] [9]. For every core, the graphcutbased strategy changed the minuscule volume in the region of the core to a mathematical volume in the round space as for the recently distinguished inward seed point and found the universally ideal surface in that mathematical volume which isolated the core from the remainder of the volume.

Xiao Lin, Josep R. states the various levelled portrayal of the crude point cloud information to adapt to these circumstances considering Image spatial availability and endeavour the fleeting data by building the worldly correspondences between the progressive structures in progressive casings. Yet, as opposed to [11], [12], we don't develop the chain of importance from a generally fine level. We rather start at an a lot more elevated level shaped by masses, fragments, segments and articles, as clarified later in Section III, so the errand of building transient correspondences can be tackled worldwide as an improvement issue on account of the diminished issue scale. Wei Liao.et.al;proposed the programmed pressure and evaluation of LSAs in Image 7T MRA images. This is a difficult errand since numerous LSAs are moderately thin and long, involve leaves behind high shape, and are frequently found near one another. Besides, despite the fact that 7T MRA contains more vessels, the sign to-commotion proportion is just somewhat higher than that of 3T MRA [13][14]. Normal difficulties of 7T MRA information incorporate high clamor level, profoundly bended vessels, low image contrast, and rounded curio.

Jørn Bersvendsen.et.al;exhibits the pressure of the LV in ImageTTE has gotten substantially more consideration in the writing, and strategies dependent on deformable models [22], [23], [24], dynamic shape models [25], dynamic appearance models [26], level-set techniques [17], and grouping [27] have been introduced. In any case, these strategies are not promptly pertinent to the RV, as there are a few difficulties that are particularly requesting for this situation, for example, an expanded anatomical intricacy and bigger between quiet variety.

Mahdi Hajiaghay.et.al;shows the information utilized for examination was a CMR dataset from Department of Diagnostic Imaging of the Hospital for Sick Children in Toronto, Canada accessible from the York University site [30] here alluded to as York data set. This information base contains short pivot cardiovascular MR images from 33 subjects along with their manual compressions of endocardial and epicardial shapes performed by an accomplished cardiologist. The York information base comprises of a heterogeneous gathering of subjects with ordinary hearts and inherent heart maladies with a mean period of 12.0 \pm 4.0.It can use either short or long-pivot CMR images or images[29] from a standard MRI in any plane (hub, coronal, sagittal) as long as they incorporate the heart.

\section{METHODOLOGY}

The classifier can be any probabilistic or vitality limiting image division calculation, in spite of the fact that probabilistic calculations are favoured since they normally encode vulnerability in the outcomes. Learning happens as the preparation information is increased, moving forward [4] the capacity of the classifier to mark unlabelled image pixels. The information is ordinarily not adequate for the classifier to deliver precise labelling and survey the uncertainty of the arrangement results. The precariousness stays over a preset edge or the client considers the division to be of deficient quality, an FL bunch question is ascertained from $U$ all together to present to the client locales of maximal vulnerability.

\section{A. IMPLEMENTATION}

Our proposed Algorithm is aIMAGE FURIORCOMPRESSION algorithm which is a classifier algorithm that establishes the class label to each pixel of the image, as it has the possibility to produce the more realistic compression of image. Hence to exhibit this calculation we use strategies introduced in [31] to build up a GPU CS usage utilizing NVIDIA's CUDA API. On premise of keeping the arrangement of image with certain tests by utilizing a few contentions and at first with $n=19$ [number of images] as discovered to be best for pressure.

\section{B. ALGORITHM}

\section{IMAGE FURIOR COMPRESSION}

INPUT: images

OUTPUT: Recognitionof images with the edges and its boundary when the size is minimized.

STEP:1 Initializing the Image

//the image assembled for the compression//

STEP:2 Checking the boundary compressing of the images.

//that is the image with approximate boundary lines on detecting the quality//

STEP:3 Guessing the visibility of the images.

$$
\begin{aligned}
& \quad \mathrm{V}(\mathrm{m}, \mathrm{n})=\partial_{\mathrm{E}} \mathrm{V}_{\mathrm{E}}(\mathrm{m}, \mathrm{p} 1(\mathrm{~m}))+\partial_{\mathrm{B}} \mathrm{V}_{\mathrm{B}}(\mathrm{m}, \mathrm{n})+\partial_{\mathrm{R}} \mathrm{V}_{\mathrm{R}}(\mathrm{m}, \mathrm{n}) \\
& +\partial_{\mathrm{S}} \mathrm{V}_{\mathrm{S}}(\mathrm{m}, \mathrm{n}), \\
& \quad \mathrm{V}_{\mathrm{E}}(\mathrm{m}, \mathrm{p} 1(\mathrm{~m}))=-\mathrm{p} 1(\mathrm{~m}) \log 2 \mathrm{p} 1(\mathrm{~m})-(1-\mathrm{p} 1(\mathrm{~m})) \log 2(1 \\
& -\mathrm{p} 1(\mathrm{~m})) . \\
& \quad \mathrm{V}_{\mathrm{B}}(\mathrm{m}, \mathrm{n})=\sum(\mathrm{Ds}(\mathrm{m}, \mathrm{n})),
\end{aligned}
$$

Where,

$\mathrm{V}(\mathrm{m}, \mathrm{n})$ implies the visibility of the images.

$\mathrm{p} 1(\mathrm{~m})=$ probability of getting the image

STEP:4 Regional compressing of the image is done by the classifier.

// the images are verified after the boundary compressingfor the specification of its unique region//

STEP:5 compressed view of the images

//the view of the functionality of images view//

\section{EFFICIENT CALCULATION}

First image F1.E1

$$
\begin{aligned}
& \mathrm{e}_{\mathrm{t}} \leftarrow \mathrm{f} 1_{t_{\mathrm{t}}} \leftarrow \mathrm{e}_{\mathrm{t}}[\mathrm{N} 1+\mathrm{Nn}] \\
& \mathrm{Fn} \leftarrow \mathrm{e}_{\mathrm{t}}\left[\mathrm{m}_{\mathrm{t}}\right] \\
& {\left[\mathrm{m}_{\mathrm{t}} \rightarrow \mathrm{e} 1 \ldots \ldots . . \mathrm{en}\right]} \\
& \mathrm{F} 1 . \mathrm{t}[\mathrm{e} 1+\mathrm{en}] / 2 \\
& \mathrm{e}_{\mathrm{t}} \rightarrow \mathrm{a}_{\mathrm{t}}[\mathrm{f} 1+\mathrm{e} 1] \\
& \mathrm{e}_{\mathrm{t}} \text { is unequal to } \mathrm{e}_{\mathrm{n}}
\end{aligned}
$$

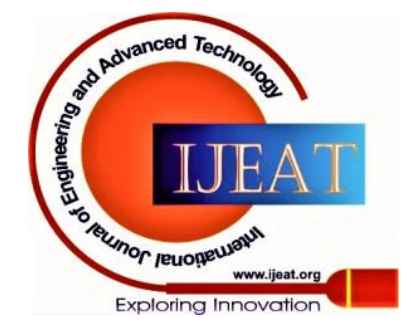


$\mathrm{e}_{\mathrm{t}} \leftarrow \mathrm{e}_{1}+\mathrm{e}_{\mathrm{n}} / \mathrm{m}_{\mathrm{t}}$

$\mathrm{m}_{\mathrm{t}} \leftarrow \mathrm{e}_{\mathrm{n}}\left[\mathrm{e}_{\mathrm{t}} / 2\right]$

$e_{t}$ not equal to $e_{n}$

F1 first image.

$\mathrm{F} 1$ is not equal to $\mathrm{Fn}$

\section{DESCRIPTION}

The above CONTIGENT STROLLER algorithm demonstrates the functionality learning of the images with the various compression visibilities on the images that is to be reached in the way of its boundary and its specified region in the Image view and its consistency to the image with the specification of images.

\section{E. IMPLEMTENTATION OVERVIEW}

The following images demonstrate the variousimage result of theIMAGE FURIOR COMPRESSION process.

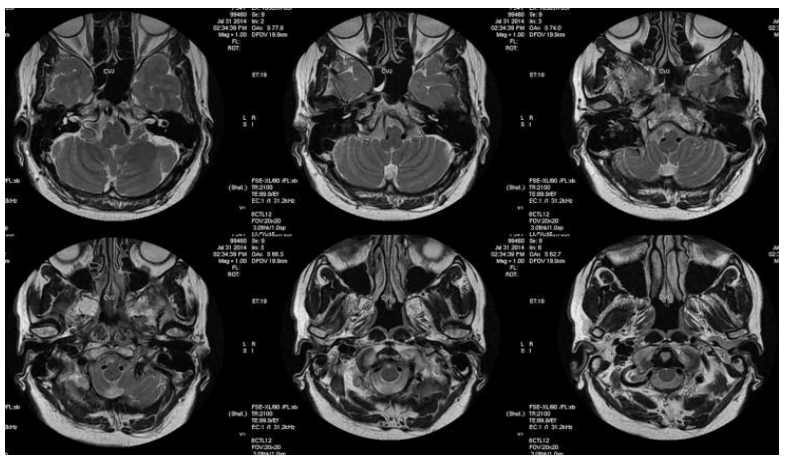

Fig.1. Functionality of the Image

The aboveimage view shows the various functionalities in the boundary of the image that is the view changes as per the edges.

\section{RESULTS AND DISCUSSIONS}

Image compression is one of, the most, vital and omnipresent undertakings in medicinal image analysis.Ourproposed system valuates image compression by building a "vulnerability field" over the image topics based on our four proposed functions.

\section{A. EFFICIENCY VIEW OF IMAGES}

The following image view shows the efficient functionality learning principle of images with the various visibilities and specifies the image in all regions.
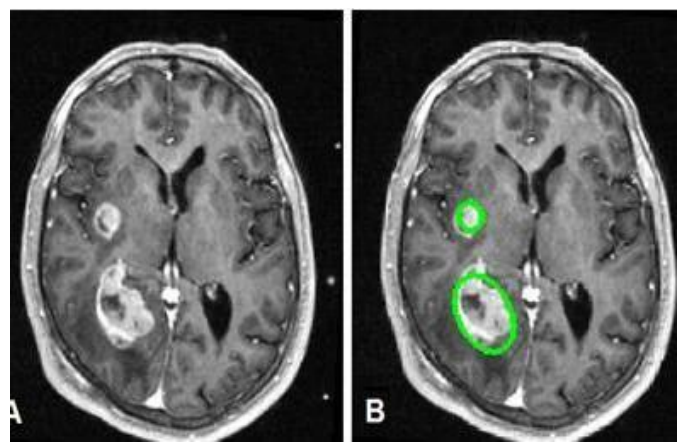

Fig.2.Image compression after the active queries were labelled

\section{B. EFFICIENCY THROUGHPUT}

Table. I. Comparison of Image view

\begin{tabular}{|l|l|c|c|}
\hline Techniques & $\begin{array}{l}\text { DSM } \\
\text { Compression }\end{array}$ & $\begin{array}{c}\text { Active } \\
\text { Contour }\end{array}$ & $\begin{array}{c}\text { IFT } \\
\text { Compression }\end{array}$ \\
\hline $\begin{array}{l}\text { Regional } \\
\text { View }\end{array}$ & 4.3 & 2.4 & 6 \\
\hline $\begin{array}{l}\text { Boundary } \\
\text { View }\end{array}$ & 2.5 & 4.4 & 7 \\
\hline $\begin{array}{l}\text { Smooth } \\
\text { View }\end{array}$ & 3.5 & 1.8 & 7.8 \\
\hline $\begin{array}{l}\text { Entropy } \\
\text { View }\end{array}$ & 4.5 & 2.8 & 8.5 \\
\hline
\end{tabular}

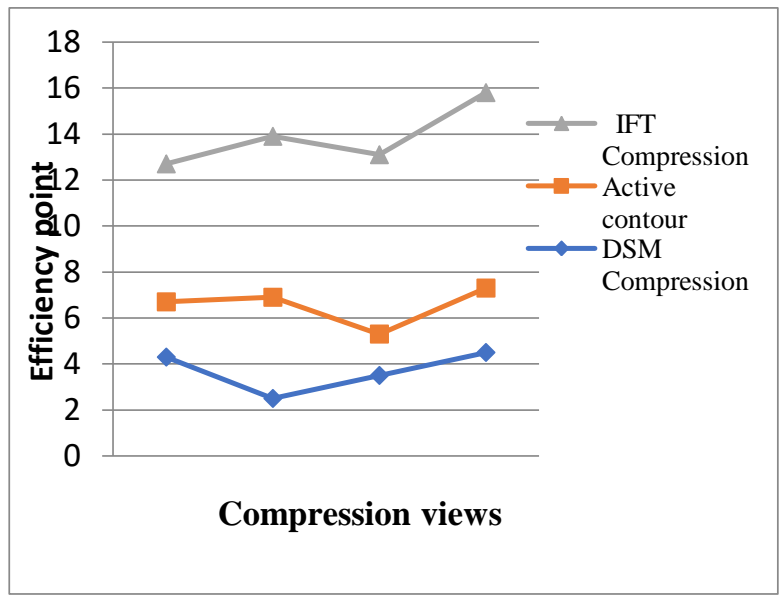

Fig.3. Efficiency comparison of the image view

The above diagram examines the effectiveness examination of the image with the current capacities took care of in image pressure. Since those cycles are profoundly proficient, it doesn't give an unmistakable throughput on explicit capacities. Be that as it may, our proposed calculation exhibits the exceptionally productive throughput.

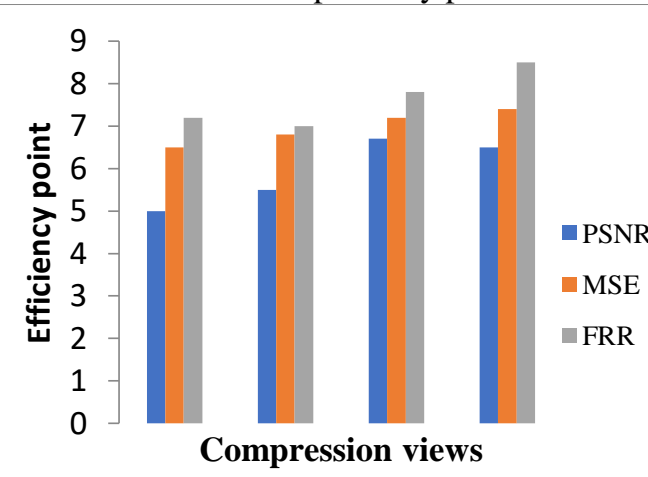

Fig.4.The false Rejection Ratio, Mean sequence error,

Peak Signal Noise Ratio for the image compression The above chart expresses the usefulness proportions of the images in different cycle. When contrasting the different pressure sees, our proposed framework shows the high productivity than other. The above proportions are the fundamental functionalities of the image pressure and are comprehensively appeared with all perspectives.

Published By:

Blue Eyes Intelligence Engineering

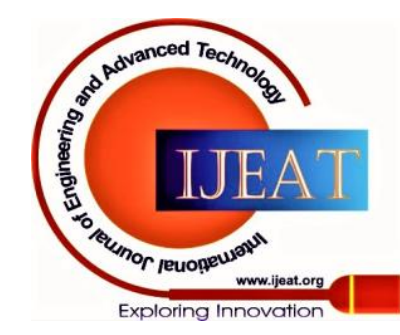




\section{An Efficient Functionality Learning Image Compression by Ift Technique}

\section{CONCLUSION}

In this paper we plan instinctive Image picture division in an AL structure. Our obligations merge being the first to plan characteristic Image picture division as a traditional FL measure. In doing appropriately, we encourage the client from picking where to give keen information. To stimulate the gathering questions, we modernize assessment of shortcoming in the depiction and moreover the yield through the soft spot generally advantageous request plane. At last, we show our technique to for the most part decrease the important client commitment to natural Image division undertakings through a customer study.

\section{FUTURE ENHANCEMENT}

Future work incorporates consolidating this strategy into other intelligent division calculations and learning the vitality utilitarian weights naturally by means of preparing information.

\section{REFERENCES}

1. Olabarriaga, S., Smeulders, A. (2001) "Interaction in the compression of medical images: a survey”. Med. Image Anal. 5(2),pp.: 127-142

2. Settles, B.: (2019)“Active learning literature survey”. Tech.Rep.1648, University of Wisconsin Madison.

3. Rafael C. Gonzalez, Richard E. Woods, 2018. "Digital Image Processing”, 2nd ed., Beijing: Publishing House of Electronics Industry,

4. Andrew Top, Ghassan Hamarneh and Rafeef Abugharbieh(2011). "Active Learning for Interactive image compression", Springer p.p:12.

5. Anca Stefanoiu, Andreas Weinmann, Martin Storath, Nassir Navab, and Maximilian Baust (2016) "Joint compression and Shape Regularization with a Generalized Forward Backward Algorithm" IEEE Transactions on Image Processing p.p:1-2

6. I. Lerchs, (1965) "Optimum design of open-pit mines," Trans. CIM, vol. 58, pp. 17-24,

7. B. Denby and D. Schofield, (1993) "Genetic algorithms: A new approach to pit optimization," in Proc. 24th Intl APCOM Symp., pp. 126-133.

8. K. Li, X. Wu, D. Chen, and M. Sonka, (2018) "Optimal surface compression in volumetric images-a graph-theoretic approach," "Pattern Analysis and Machine Intelligence" IEEE Transactions on, vol. 28, no. 1, pp. 119-134

9. Kaustav Nandy, Rama Chellappa, Amit Kumar, and Stephen J Lockett (2015) "compression of Nuclei from Image Microscopy Images of Tissue via Graphcut Optimization" IEEE Journal of Selected Topics in Signal Processing p.p:1-2

10. Xiao Lin, Josep R. Casas, and Montse Pardas (2015) "Temporally Coherent Image Point Cloud Video compression in Generic Scenes" IEEE Journal of Selected Topics in Signal Processing.

11. M. Grundmann, V. Kwatra, M. Han, and I. Essa.(2019) "Efficient hierarchical graph-based video compression". In Computer Vision and Pattern Recognition (CVPR), 2019 IEEEConference on, p.p:2141-2148.

12. S. Hickson, S. Birchfield, I. Essa, and H. Christensen(2014). "Efficient hierarchical graph-based compression of rgbd videos". In CVPR2014. IEEE Computer Society. p.p:1-2

13. Wei Liao, Karl Rohr, Chang-Ki Kang, Zang-Hee Cho and Stefan Wörz (2016) "Automatic Image compression and Quantification of Lenticulostriate Arteries from High-Resolution 7 Tesla MRA Images" IEEE TRANSACTIONS ON IMAGE PROCESSING, VOL. 25p.p:401-402.

14. X. Wu, V. Luboz, K. Krissian, S. Cotin, and S. Dawson(2011.), "compression and reconstruction of vascular structures for Image real-time simulation,” Med. Image Anal., vol. 15, no. 1, pp. 22-34.

15. Bulat Ibragimov, Robert Korez, Bostjan Likar, Franjo Pernu s, Lei Xing, and Tomaz Vrtovec(2017) "compression of Pathological Structures by Landmark-Assisted Deformable Models" IEEE Transactions on Medical Imaging p.p:2-3.

16. Shen, T., Li, H., Huang, X(2011) "Active volume models for medical image compression", IEEE Trans. Med. Imaging, 30, 774-791.

17. E. D. Angelini et al. (2005) "compression of real-time threedimensional ultrasound for quantification of ventricular function: a clinical study on right and left ventricles." Ultrasound in medicine \& biology, vol. 31, no. 9, pp. 1143-58,

18. Tan, C., Yan, Z., Li, K., Metaxas, D., Zhang, S. (2015) "Laplacian shape editing with local patch based force field for interactive compression," In: Proc. 2nd Int. Workshop on Patch-Based Tech. in Med. Imaging. p.p:95-193

19. Chiang, P., Zheng, J., Hou Mak, K., Magnenat Thalmann, N., Cai, Y. (2012) "Progressive surface reconstruction for heart mapping procedure", Computer.-Aided Design 44, p.p:289-299

20. Yu, Y., Zheng, S., Li, K., Metaxas, D., Axel, L.: (2014) "Deformable models with sparsity constraints for cardiac motion analysis", Med. Image Anal. 18, p.p:927-937

21. Kronman, A., Joskowicz, L. (2013): "Image compression errors correction by mesh compression and deformation" In: Proc. Med. Image Compute and Computer-Assist. Interven. (MICCAI-2013) p.p:218-213.

22. Chartrand, G., Cresson, T., Chav, R., Gotra, A., Tang, A., DeGuise, J(2014) "SEMI-automated liver CT compression using Laplacian meshes", In: Proc. 2014 IEEE 11th Int. Symp. on Biomed. Imaging (ISBI-2014) p.p:641-644.

23. Jørn Bersvendsen, Fredrik Orderud, Richard John Massey, Kristian Fossa, Olivier Gerard, Stig Urheim, and Eigil Samset(2015) "Automated compression of the Right Ventricle in Image Echocardiography: A Kalman Filter State Estimation Approach" IEEE Transactions on Medical Imaging.p.p:1-2.

24. F. Orderud, (2018). "A Framework for real-time left ventricular tracking in $3 \mathrm{D}+\mathrm{T}$ echocardiography, using nonlinear deformable contours and kalman filter based tracking," in Computers in Cardiology, 2018. IEEE, Sept 2018, pp. 125-128.

25. J. Hansegard, S. Urheim, K. Lunde, S. Malm, and S. Rabben, (2009) "Semiautomated quantification of left ventricular volumes and ejection fraction by real-time three-dimensional echocardiography," Cardiovascular Ultrasound, vol. 7, no. 1, pp. 18,

26. J. Hansegard, F. Orderud, and S. I. Rabben, (2018) "Real-time active shape models for compression of Image cardiac ultrasound," in Computer Analysis of Images and Patterns, ser. Lecture Notes in Computer Science. Springer Berlin Heidelberg, vol. 4673, pp. 157164.

27. K. Y. E. Leung et al. (2008) "Improving Image active appearance model compression of the left ventricle with jacobian tuning," in Proc. SPIE 6914, Medical Imaging 2008: Image Processing, vol. 6914,

28. B. Georgescu, X. Zhou, D. Comaniciu, and A. Gupta, (2005) "Database-guided compression of anatomical structures with complex appearance," in Computer Vision and Pattern Recognition, 2005. IEEE Computer Society Conference on, vol. 2, June 2005, pp. 429436.

29. Mahdi Hajiaghayi, Elliott M. Groves., M.Eng., Hamid Jafarkhani, (2016) "A Image Active Contour Method for Automated compression of the Left Ventricle from Magnetic Resonance Images" IEEE Transactions on Biomedical Engineering.p.p:1-2.

30. Kajal Gautam, Dr. Rahul Singhai.(2017) "A REVIEW: DIGITAL IMAGE compression TECHNIQUES" International journal of engineering sciences \& research technology.p.p:351-354

31. Grady, L., Schiwietz, T., Aharon, S., Westermann, R. (2005): "Random walks for interactive organ compression in two and three dimensions: Implementation and validation". In: Duncan, J., Gerig, G. (eds.) MICCAI. LNCS, vol. 3750, Springer Berlin / Heidelberg pp. 773-780.

32. Ersoy I, Bunyak F, Mackey M, Palaniappan K(2008) "Cell compression Using Hessian - Based Detection and Contour Evolution with Directional Derivative"s. International Conference on Image Processing p.p:1804-1818.

33. Li, K., Miller, E., Weiss, L., Campbell, P., and Kanade, T. (2018) "Online tracking of migrating and proliferating cells imaged with phase - contrast microscopy". Proc. of the Conf, on Computer Vision and Pattern Recognition Workshop (CVPRW'18), p.p: 65-72.

34. P.Soundarajan. Dr.S.Selvamuthukumaran“Image Analysing Using Improved Space Invariant Feature Transform (ISIFT) Technique"

35. Palaniappan K, Ersoy I, Nath SK (2018): "Moving Object compression Using the Flux Tensor for Biological Video Microscopy". Lect Notes Computer Sci., 4819(LNCS)p. p:483-493.

36. P.Soundarajan, Dr.S. Selvamuthukumaran, "Robust Image Face Recognition Image Compression Using VCAD (Vector color and Depth Analysis)"

Published By:

Blue Eyes Intelligence Engineering and Sciences Publication (C) Copvriaht: All riahts reserved. 
37. H. G. Kaganami, Z. Beij (2009)“Region Based Detection versus Edge Detection", IEEE Transactions on Intelligent information hiding and multimedia signal processing, pp. 1217-1221.

\section{AUTHORS PROFILE}

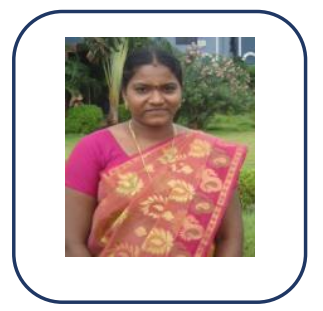

C.Rajeswari, ispursuing Ph.D. in SCSVMV University, Kanchipuram. My deepest area is Image Compression and more interest in Mathematics. Currently I am working as Assistant Professor in Soka Ikeda College of Arts and Science for Women, Chennai, India. I presented many papers and participated in various workshops.I published many journals in National and International Publications.

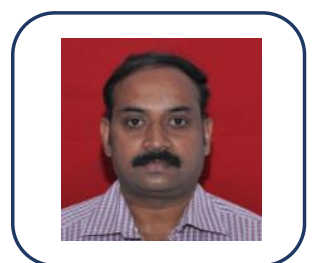

Dr S.Prakasam, is working as Associate Professor, Department of Computer Science \& Applications, SCSVMV University, Kanchipuram, India.He guided many Ph.D. scholars and published many national and International journals. His area of Interest lies in E-learning, First-Aid E-learning. He is more interested in research area as Software Engineering, Data Mining and Data Communication \& Networking.

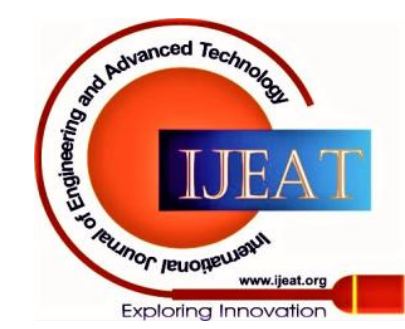

